\title{
Effects of Low-dose Milrinone on Weaning from Cardiopulmonary Bypass and after in Patients with Mitral Stenosis and Pulmonary Hypertension
}

\author{
İlhan ÖZTEKIN,$^{a}$ Şenol YAZICI, ${ }^{b}$ Deniz S. ÖZTEKIN, ${ }^{*, c}$ Onur GöKSEL, ${ }^{a}$ \\ Halim İSSEVER, ${ }^{d}$ and Sevim CANIK ${ }^{a}$ \\ aAnesthesiology Department, Siyami Ersek Thoracic and Cardiovascular Surgery Hospital, Haydarpaşa, \\ İstanbul, Turkey, ${ }^{b}$ Anesthesiology Department, Balta Limanı Bone Diseases Hospital, Istanbul, \\ Turkey, 'Surgical Nursing Department, Florence Nightingale College of Nursing, Istanbul \\ University, Istanbul, Turkey, and ${ }^{d}$ Department of Public Health, Medical \\ Faculty, Istanbul University, Istanbul, Turkey
}

(Received August 24, 2006; Accepted October 17, 2006)

\begin{abstract}
The phosphodiesterase inhibitor milrinone is usually preferred in patients with pulmonary hypertension and myocardial dysfunction after cardiopulmonary bypass. We investigated the effects of low-dose milrinone on pulmonary hypertension in the immediate pre- and postoperative period. Forty-seven patients were randomized to the control and milrinone groups. All patients had mean pulmonary artery pressure greater than $30 \mathrm{mmHg}$ and pulmonary capillary wedge pressure greater than $20 \mathrm{mmHg}$ and were candidates for mitral valve replacement for rheumatic mitral stenosis. Twenty-four patients received a loading dose of milrinone $25 \mu \mathrm{g} / \mathrm{kg}^{-1}$ during weaning from cardiopulmonary bypass, followed by a maintenance dose of $0.25 \mu \mathrm{g} / \mathrm{kg}^{-1} / \mathrm{min}^{-1}$ to the end of the surgery. Cardiac output and other hemodynamic variables were noted at induction, weaning from bypass, and postoperative $1 \mathrm{~h}$. Pulmonary artery pressure, capillary wedge pressure, and central venous pressure were significantly lower in the milrinone group during weaning after cardiopulmonary bypass, while other variables were roughly similar. However, patients in the control group required higher doses of vasodilators, inotropes, and antiarrhythmic agents. Mean arterial pressure in the milrinone group was significantly lower at $1 \mathrm{~h}$ postoperatively than in the control group; however, the patients did not need many more vasopressors. Fluid restriction and diuretic agent use were more significant in the control group. Systemic arterial hypotension and vasopressor requirements with milrinone use at inotropic doses were not observed at the doses used for the study. A total of $21.7 \%$ of the patients in the control group required vasopressors in the perioperative period. Both groups demonstrated similar hematologic variables except that the hemoglobin level in the control group was significantly lower during postoperative days 1 and 7. Low-dose milrinone for a short-term during weaning from cardiopulmonary bypass may be used in patients with mitral stenosis and pulmonary hypertension for its effects on pulmonary artery pressures, less inotropic and vasopressor requirements, and fluid balance.
\end{abstract}

Key words_— milrinone; cardiopulmonary bypass; mitral stenosis; pulmonary hypertension

\section{INTRODUCTION}

Weaning from cardiopulmonary bypass (CPB) can be difficult in cardiac surgery patients due to various reasons such as intrinsic myocardial dysfunction, inadequate myocardial protection, or high pulmonary vascular resistance (PVR). ${ }^{1)}$ In patients with longstanding mitral stenosis and a history of congestive heart failure $(\mathrm{CHF})$ in particular, weaning from bypass can be cumbersome although the valvular pathology is terminated during the operation. ${ }^{1)}$ Such myocardial dysfunction at this stage has a deteriorating effect on many organ systems, often necessitating further manipulations or interventions such as tem-

\footnotetext{
*e-mail: dnzoztekin@ hotmail.com
}

porary pacing, vasodilator therapy, and diuretics. Difficulties at this stage may also indicate further problems that the patient may have in the postoperative period. An inotropic agent not affecting adrenergic receptors is preferable in CHF since a state of "down regulation of $\beta$ receptors" with high catecholamine levels is present in these patients. ${ }^{2)}$

Phosphodiesterase type III (PDE III) inhibitors like milrinone are used in acute or chronic heart failure for their positive inotropic, lusitropic, and vasodilator effects. ${ }^{3,4)}$ Positive inotropic effects in addition to a combined decrease in after- and preload is are why myocardial oxygen consumption does not increase. ${ }^{2,3)}$ Ventricular filling is better even at high heart rates due to their beneficial effects on diastolic heart function and thus results in better coronary 
perfusion. ${ }^{2,3)}$ Milrinone also has direct vasodilatory effects on coronary arteries, lowering coronary arterial resistance by $30-40 \% .5,6)$

During CPB and in the reperfusion period, increased levels of cytokines such as tumor necrosis factor (TNF) were reported to be a result of myocardial stunning, respiratory distress syndromes, renal failure, pancreatitis, or neurologic syndromes. ${ }^{7)}$ These cytokines were held responsible for reperfusion myocardial damage. TNF has detrimental effects on endothelium, causing a local inflammatory response and thrombosis; myocardial ischemia and even functional depression were reported. PDE inhibitors were shown to reduce TNF levels during CPB and counteract its negative effects. ${ }^{7-11)}$ This may be partly due to milrinone's inhibitory effects on phagocytotic and adherence activities of leukocytes. ${ }^{3)}$ Bronchial smooth muscle relaxation by milrinone is beneficial to avoid bronchoconstrictive states induced by the inflammatory response.

In recent years, PDE III inhibitors have been effectively used during weaning from bypass because of their positive inotropic effects as well as the fact that they reduce systemic vascular resistance (SVR) and PVR with additional recovery of intrinsic myocardial dysfunction. ${ }^{1,12-18)}$ Janelle et al. ${ }^{19)}$ showed that the administration of a single dose of milrinone before aortic cross-clamping resulted in a significantly higher intramyocardial cyclic adenosine monophosphate concentration in myocardial biopsy specimens compared with controls. PDE III inhibitors may cause hypotensive episodes at inotropic doses and may require the addition of a vasoconstrictive medication. ${ }^{12}$ )

Several author ${ }^{20)}$ recommend variable doses of milrinone due to its aforementioned benefits; however, its effects during and immediately after weaning bypass have been poorly defined. At this stage of open heart surgery, drugs may have variabilities in pharmacokinetics and pharmacodynamics due to specific features of CPB such as hemodilution, changes in regional blood flow, and hypothermia. ${ }^{12}$ Milrinone loading with $50 \mu \mathrm{g} / \mathrm{kg}$ given over $10 \mathrm{~min}$ in the intensive care unit (ICU) may cause severe hypotensive episodes in open heart surgery patients and thus require vasopressors. This has caused a tendency of giving lower doses over longer periods. ${ }^{12}$

Purpose In this study, we aimed to investigate the effects of lower doses of milrinone $(25 \mu \mathrm{g} / \mathrm{kg}$ loading and $0.25 \mu \mathrm{g} / \mathrm{kg} / \mathrm{min}$ maintenance doses) on the reduction of adverse events in the stage of weaning from bypass and in the postoperative period. This is also the first study to demonstrate the major role of perianesthesia nursing care in hemodynamic improvement in the clinical setting in patients with pulmonary hypertension and mitral stenosis receiving low-dose milrinone therapy during weaning from CPB.

Design This study was designed as a prospective, randomized, and controlled trial.

Sample Patients scheduled to undergo open heart surgery for mitral stenosis were included in the study after local institutional scientific and ethic committee approval was obtained. Patients' informed consent are obtained. Among these patients, those with preoperative mean pulmonary artery pressure (MPAP) of greater than $30 \mathrm{mmHg}$ and pulmonary capillary wedge pressure (Pcwp) more than 20 $\mathrm{mmHg}$ with direct catheterization were enrolled in the study group. Patients older than 70 or younger than 20 years and those with overt hepatic or renal dysfunction were excluded from the study. Also, uncontrolled supraventricular tachycardia and preoperative platelet (Plat) count of less than 100000/1 were other two criteria for exclusion from the study group.

\section{METHODS}

The baseline vital signs and abnormalities, renal status, and neurologic status were reviewed preoperatively by researcher nurse, who informed the primary investigator of abnormal values. The extremities and sacrum were examined for edema, peripheral pulses were located, and the presence of chronic atrial fibrillation were noted by the researcher nurse who informed primary investigator. ${ }^{21)}$ Relevant preoperative information was gathered by the researcher nurse throughly patient information (or interview of the family or significant others), noninvasively and invasively, especially additional chemistry profiles for preanesthesia care according to the American Society of PeriAnesthesia Nurses (ASPAN) standards of nursing practice. ${ }^{21)}$

Patients in class 3 according to classification of the American Society of Anesthesiologists (ASA-3) were randomly assigned to either the study (Grp I; 24 patients) or control (Grp II; 23 patients) group. All patients received standard premedication with oral diazepam $10 \mathrm{mg}$ on the night before surgery as well as intramuscular morphine $10 \mathrm{mg}$ and scopolamine 0.5 $\mathrm{mg} 60 \mathrm{~min}$ before surgery. Leads II and $\mathrm{V}_{5}$ elec- 
trocardiography (ECG) and direct invasive arterial monitorization with Horizon XL (Mennen Medical Inc.) were performed in the operating room. Radial arterial puncture with a $20 \mathrm{G}$ angiocath was used. A standard peripheral venous line was established from the brachial vein with a $16-18 \mathrm{G}$ catheter. All patients received anesthetic induction with fentanyl $20 \mu \mathrm{g} / \mathrm{kg}$, propofol $1.5-2 \mathrm{mg} / \mathrm{kg}$, and pancuronium bromide $0.1 \mathrm{mg} / \mathrm{kg}$. With adequate muscle relaxation, endotracheal intubation was performed with inhalation of $100 \%$ oxygen and was followed by insertion of a right jugular vein catheter and a pulmonary artery (PA) thermodilution catheter (Abbott 7F, 4 lumens, $110 \mathrm{~cm})$. Maintenance was achieved with fentanyl $5 \mu \mathrm{g} / \mathrm{kg} / \mathrm{hr}$, propofol $1.5 \mathrm{mg} / \mathrm{kg} / \mathrm{hr}$, and pancuronium bromide $0.05 \mathrm{~g} / \mathrm{kg}$ once each hour intravenously. For monitoring of systemic arterial and cardiac filling pressures, Bıçakçılar transducer systems were used. Mild hypothermia $\left(28-30^{\circ} \mathrm{C}\right)$ and antegrade cold crystalloid cardioplegic arrest with aortic clamping were used. All patients had mitral valve replacement with a mechanical prosthetic valve. During CPB, membrane oxygenators (Dideco) were used and patient hematocryte (Hct) was maintained between $22-24 \%$ at flow rates of $2-31 / \mathrm{min} / \mathrm{m}^{2}$ and $70-90 \mathrm{mmHg}$ of systemic perfusion pressure.

In the milrinone group, a $25 \mu \mathrm{g} / \mathrm{kg}^{-1}$ intravenous loading dose of milrinone given over 20 min was followed by a $0.25 \mu \mathrm{g} / \mathrm{kg} / \mathrm{min}$ intravenous maintenance dose of the same drug during left atrial closure before the aortic clamp was removed. Intravenous infusion of milrinone was stopped during closure of the chest incision. Anesthesiologists were allowed to administer further inotropes or any other drug in either group if considered necessary.

Hemodynamic variables such as mean arterial pressure (MAP), central venous pressure (CVP), heart rate (HR), intracardiac, pulmonary artery, and wedge pressures, etc. were assessed at anesthesia induction, bypass weaning and at $1 \mathrm{~h}$ postoperatively using thermodilution method. Isotonic saline $10 \mathrm{cc}(0$ $-5^{\circ} \mathrm{C}$ ) was given at each session of measurements (three times with the mean recorded) with a BaxterCoset-Abbott Cardiac Output Computer 3300. Cardiac output (CO) ( $1 / \mathrm{min})$ and its derived variables such as cardiac index (CI) $\left(1 / \mathrm{min} / \mathrm{m}^{2}\right)$, SVR $\left(\right.$ dyne $\left.{ }^{*} \mathrm{sec} / \mathrm{cm}^{5}\right), \quad$ PVR $\left(\right.$ dyne* $\left.\mathrm{sec} / \mathrm{cm}^{5}\right)$, stroke volume index (SVI), left ventricular stroke work index (LVSWI) and right ventricular stroke work index
(RVSWI) were recorded as well as the need for any other drug (inotrope, nitroglycerine, antiarrhythmic etc.) during weaning from $\mathrm{CPB}$ and after (e.g. in the postoperative ICU). Fluid balance including surgical hemorrhage was recorded during the operation and in the ICU.

Preoperative, postoperative minute 30 and day 1 and 7 complete blood counts, Hct, and hemoglobin $\mathrm{Hb})$ measurements, and lengths of ICU and hospital stay were recorded by the researcher nurse.

Statistical Analysis Descriptive statistics (mean, standard deviation) were used to summarize the data. Two-way ANOVA for repeated measures was used to examine differences between the two groups in the trial. Mauchly's test of sphericity was significant for all parameters, and therefore multivariate tests were used with consideration of Wilks' lambda. The paired $t$-test was used for parameters where there was a significant interaction between trial group and time. The Bonferroni corrected paired $t$ test was used to examine paired comparisons within groups. The Bonferroni corrected $t$-test was used to examine differences between groups.

In multivariate comparisons between groups, the baseline (preop-control values) were taken into account to account for the baseline biological values. Friedman and Mann-Whitney U-tests were used for parameters in hemorrhagic profiles and fluid balances. Statistical significance was accepted at $p<$ 0.05 and two-tailed.

Ethics Permission to conduct the study was obtained from the local institutional scientific and ethic committee of our hospital. The nature of the study was explained to all unit consultants, the nursing director, chief director of the Anaesthesia and Reanimation Department, and members of the multidisciplinary team who have significant input into the patients' weaning from $\mathrm{CPB}$ and in the postoperative period.

Anonymity of participants was guaranteed and protection of the participants was of paramount importance. Relatives of the patients included in the study were informed by the primary investigator and researcher nurse, and informed consent was obtained from patients or their family members for surgery.

\section{RESULTS}

Tables 1 and 2 demonstrate that the two groups were similar in patient demographics and preopera- 
tive catheterization findings. Baseline pulmonary artery pressure (PAP) and Pcwp levels were higher in Grp I than in Grp II; however, the levels of these two variables were similar after weaning from $\mathrm{CPB}$, indicating a more significant drop in Grp I (PAP: 22.5/ 21.8 mmHg; Pcwp: $14.2 / 11.3 \mathrm{mmHg}$ ), and the drop in Pcwp at $1 \mathrm{~h}$ postoperatively in Grp I was significantly different than in Grp II (Table 3$),(p<$ 0.05 ). Additionally, a more pronounced, but not statistically significant, decrease in PVR was observed in Grp I (from $221.16 \pm 110.895 \mathrm{dyn} . \mathrm{sn} / \mathrm{cm}^{5}$ to $126.25 \pm 68.580$ dyn.sn/ $\mathrm{cm}^{5}$ in Grp I; from $223.21 \pm$ $223.562 \mathrm{dyn} . \mathrm{sn} / \mathrm{cm}^{5}$ to $189.56 \pm 179.619 \mathrm{dyn} . \mathrm{sn} / \mathrm{cm}^{5}$ in Grp II) $(p>0.05)$. Baseline SVR levels were significantly different in the two groups, and the level of decrease in SVR was similar between Grp I and II (from $1593.25 \pm 459.876 \mathrm{dyn} . \mathrm{sn} / \mathrm{cm}^{5}$ to $1021.08 \pm$

Table 1. Patient Demographics

\begin{tabular}{lccc}
\hline \hline & $\begin{array}{c}\text { Milrinone } \\
n=24\end{array}$ & $\begin{array}{c}\text { Control } \\
n=23\end{array}$ & $p$ value \\
\hline Male $/$ Female & $22 / 2$ & $20 / 3$ & 0.48 \\
\hline Height $(\mathrm{cm})$ & $165.91 \pm 10.25$ & $161.52 \pm 8.88$ & 0.123 \\
\hline Weight $(\mathrm{kg})$ & $67.75 \pm 13.4$ & $61.13 \pm 9.21$ & 0.055 \\
\hline BSA $\left(\mathrm{cm}^{2} / \mathrm{kg}\right)$ & $1.74 \pm 0.199$ & $1.64 \pm 0.15$ & 0.055 \\
\hline Age $($ years $)$ & $47.25 \pm 10.53$ & $42.6 \pm 10.81$ & 0.143 \\
\hline
\end{tabular}

BSA: body surface area.

Table 2. Preoperative Hemodynamic Measurements during Swan-Ganz Pulmonary Artery Catheterization

\begin{tabular}{cccc}
\hline \hline $\begin{array}{c}\text { Pressure in } \\
\text { heart chamber } \\
(\mathrm{mmHg})\end{array}$ & $\begin{array}{c}\text { Milrinone } \\
n=24\end{array}$ & $\begin{array}{c}\text { Control } \\
n=23\end{array}$ & $p$ value \\
\hline $\mathrm{RA}$ & $12.83 \pm 5.561$ & $9.18 \pm 4.1$ & $0.015^{*}$ \\
\hline $\mathrm{RVs}$ & $55.25 \pm 14.85$ & $56.69 \pm 18.51$ & 0.768 \\
\hline $\mathrm{RVd}$ & $10.83 \pm 5.54$ & $8.82 \pm 3.48$ & 0.146 \\
\hline PAs & $57.16 \pm 15.27$ & $57.47 \pm 16.82$ & 0.947 \\
\hline PAd & $29.5 \pm 12.42$ & $28.43 \pm 9.5$ & 0.743 \\
\hline Pcwp & $31 \pm 6.9$ & $28.6 \pm 7.57$ & 0.263 \\
\hline LVs & $130.83 \pm 21.45$ & $131.52 \pm 15.03$ & 0.899 \\
\hline LVd & $10.5 \pm 5.57$ & $10.82 \pm 4.11$ & 0.821 \\
\hline AOs & $130.83 \pm 21.45$ & $133.84 \pm 17.64$ & 0.663 \\
\hline AOd & $75 \pm 7.8$ & $73.91 \pm 11.47$ & 0.704 \\
\hline
\end{tabular}

S: systolic, d: diastolic, RA: right atrium, RV: right ventricle, PA: pulmonary artery, Pcwp: pulmonary capillary wedge pressure, LV: left ventricle, AO: aorta. $* p<0.05$.
$298.041 \mathrm{dyn} . \mathrm{sn} / \mathrm{cm}^{5}$ in Grp I; from $2074.3 \pm 875.909$ dyn.sn $/ \mathrm{cm}^{5}$ to $1255.56 \pm 340.365 \mathrm{dyn} . \mathrm{sn} / \mathrm{cm}^{5}$ in Grp II) $(p>0.05)$. Similar but not significant increase in $\mathrm{CO}$ were observed in both groups (from $4.18 \pm 0.831$ $/ \mathrm{min}$ to $5.5 \pm 1.27 \mathrm{l} / \mathrm{min}$ in Grp I; from $3.5 \pm 1.33 \mathrm{l} /$ $\min$ to $4.77 \pm 1.23 \mathrm{l} / \mathrm{min}$ in Grp II) $(p>0.05)$. There was a significant drop in CVP in Grp I after weaning from CPB (from 11.25 to $9.85 \mathrm{mmHg}$ in Grp I; from 7.78 to $8.08 \mathrm{mmHg}$ in Grp II) $(p<0.05)$. The decrease in MAP in Grp I was significantly greater than in control at $1 \mathrm{~h}$ postoperatively (from 91.66 to $78.83 \mathrm{mmHg}$ in Grp I; from 88.26 to $85.04 \mathrm{mmHg}$ in Grp II) $(p<0.05)$. However, the decrease was in the normal clinical range.

Grp II required significantly more vasodilator agents (82\% vs. $16 \%)$, vasopressor agents $(21.7 \%$ vs. $0 \%)$, inotropes $(47 \%$ vs. $8 \%)$, and antiarrhythmic agents (43\% vs. $8 \%)$ than Grp I (Table 4) $(p<0.05)$.

In the postoperative ICU, the need for vasodilator agents was more pronounced in Grp II despite the fact that milrinone was not given in the ICU $(73 \%$ vs. $33 \%$ within 24 h postoperatively; $43 \%$ vs. $26 \%$ on postoperative day 1) (Table 5), $(p<0.05)$. The need for inotropes was less in Grp II in the ICU (26\% vs. $16 \%$ ), although this was not a statistically significant finding. Review of antiarrhythmic agent use in the ICU revealed similar incidences in both groups on the first day postoperatively; however, Grp I showed a significantly better performance on postoperative day 1 with virtually no patient on an antiarrhythmic drug. Grp II had 7 patients who required antiarrhythmic treatment 17 times in total $(p<0.05)$. Hb levels in Grp I were decreased significantly less than in Grp II on postoperative days 1 and 7 (Table 6) $(p<0.05)$. Hct. and Plat. were similar in both groups at all time points $(p>0.05)$. Additionally, only a slight and insignificant increase in hemorrhage from mediastinal and thoracic tubes was seen in Grp I (from 950 to 450 $\mathrm{ml}$ as median) in comparison to Grp II (from 700 to $120 \mathrm{ml}$ as median $)(p>0.005)$. It is noteworthy that CPB (Grp I: $108.583 \pm 42.396$, Grp II: $109.217 \pm$ $27.072 \mathrm{~min}$ ) and cross-clamping times (Grp I: 87.75 \pm 33.715 , Grp II: $79.782 \pm 26.805 \mathrm{~min})$ as well as ICU (Grp I: $2.25 \pm 0.737$, Grp II: $2.173 \pm 0.576$ days) and hospital stay (Grp I: $9.083 \pm 2.339$, Grp II: $10.652 \pm 4.216$ days $)$ were similar in both groups, $(p$ $>0.05)$. As an interesting note, less need for a negative fluid balance with diuretics was observed in Grp I 
Table 3. Comparison of the Hemodynamic Values between the Two Groups

\begin{tabular}{|c|c|c|c|c|}
\hline (mmHg) & Milrinone $(n=24)$ & Control $(n=23)$ & \multicolumn{2}{|c|}{ Two-tailed significance } \\
\hline MAP. 1 & $91.66 \pm 10.209$ & $88.26 \pm 14.970$ & & \\
\hline MAP. 2 & $75.58 \pm 8.272 * * *$ & $78.91 \pm 9.356^{* *}$ & $\mathrm{~F}=1.38$ & $p=0.24$ \\
\hline MAP. 3 & $78.83 \pm 10.953^{* *}$ & $85.04 \pm 12.607 \mathrm{nd}$ & $F=6.93$ & $p=0.011$ \\
\hline \multicolumn{5}{|l|}{$(\mathrm{mmHg})$} \\
\hline CVP. 1 & $11.25 \pm 5.869$ & $7.78 \pm 5.984$ & & \\
\hline CVP. 2 & $8.584 \pm 4.200 \mathrm{nd}$ & $8.08 \pm 3.301 \mathrm{nd}$ & $\mathrm{F}=5.42$ & $p=0.02$ \\
\hline CVP. 3 & $7.66 \pm 4.239 \mathrm{nd}$ & $7.26 \pm 3.193 \mathrm{nd}$ & $\mathrm{F}=3.71$ & $p=0.06$ \\
\hline \multicolumn{5}{|l|}{$(\mathrm{mmHg})$} \\
\hline PA. 1 & $38.16 \pm 16.348$ & $26.65 \pm 18.117$ & & \\
\hline PA. 2 & $22.58 \pm 5.963^{* * *}$ & $21.82 \pm 11.215^{*}$ & $\mathrm{~F}=4.45$ & $p=0.040$ \\
\hline PA. 3 & $21.75 \pm 7.780^{* * *}$ & $21.34 \pm 8.932^{*}$ & $\mathrm{~F}=3.46$ & $p=0.06$ \\
\hline \multicolumn{5}{|l|}{$(\mathrm{mmHg})$} \\
\hline Pcwp. 1 & $26.75 \pm 12.137$ & $16.69 \pm 8.243$ & & \\
\hline Pcwp. 2 & $14.25 \pm 6.394 * * *$ & $11.26 \pm 4.524^{* *}$ & $\mathrm{~F}=10.02$ & $p=0.002$ \\
\hline Pcwp. 3 & $12.33 \pm 6.780^{* * *}$ & $10.82 \pm 4.249^{* * *}$ & $\mathrm{~F}=12.79$ & $p=0.001$ \\
\hline \multicolumn{5}{|l|}{ (beat/min.) } \\
\hline HR. 1 & $90.41 \pm 17.680$ & $90.86 \pm 15.052$ & & \\
\hline HR. 2 & $93.91 \pm 21.477 \mathrm{nd}$ & $92.52 \pm 14.189 \mathrm{nd}$ & $\mathrm{F}=0.059$ & $p=0.80$ \\
\hline HR. 3 & $95 \pm 26.771 \mathrm{nd}$ & $93.73 \pm 14.308 \mathrm{nd}$ & $\mathrm{F}=0.06$ & $p=0.80$ \\
\hline \multicolumn{5}{|l|}{ (lt/min.) } \\
\hline CO. 1 & $4.18 \pm 0.832$ & $3.5 \pm 1.339$ & & \\
\hline CO. 2 & $5.5 \pm 1.277^{* *}$ & $4.77 \pm 1.235^{* * *}$ & $\mathrm{~F}=0.10$ & $p=0.75$ \\
\hline CO. 3 & $5.31 \pm 1.430^{* *}$ & $4.62 \pm 1.512^{* * *}$ & $\mathrm{~F}=0.02$ & $p=0.88$ \\
\hline \multicolumn{5}{|l|}{$\left(\mathrm{lt} / \mathrm{min} . / \mathrm{m}^{2}\right)$} \\
\hline CI. 1 & $2.38 \pm 0.39$ & $2.11 \pm 0.73$ & & \\
\hline CI. 2 & $3.2 \pm 0.855^{* *}$ & $2.91 \pm 0.749^{* * *}$ & $\mathrm{~F}=0.00$ & $p=0.98$ \\
\hline CI. 3 & $3.06 \pm 0.821^{* *}$ & $2.81 \pm 0.839^{* * *}$ & $\mathrm{~F}=0.02$ & $p=0.86$ \\
\hline \multicolumn{5}{|l|}{$\left(\right.$ dyn. $\left.\mathrm{sn} / \mathrm{cm}^{5}\right)$} \\
\hline PVR. 1 & $221.16 \pm 110.895$ & $223.21 \pm 223.562$ & & \\
\hline PVR. 2 & $126.25 \pm 68.580^{* *}$ & $189.56 \pm 179.619$ nd & $\mathrm{F}=1.89$ & $p=0.17$ \\
\hline PVR. 3 & $151.5 \pm 81.146^{*}$ & $204.478 \pm 160.483 \mathrm{nd}$ & $\mathrm{F}=1.82$ & $p=0.18$ \\
\hline \multicolumn{5}{|l|}{$\left(\right.$ dyn. $\left.\mathrm{sn} / \mathrm{cm}^{5}\right)$} \\
\hline SVR. 1 & $1593.25 \pm 459.876$ & $2074.3 \pm 875.909$ & & \\
\hline SVR. 2 & $1021.08 \pm 298.041^{* * *}$ & $1255.56 \pm 340.365^{* * *}$ & $\mathrm{~F}=3.17$ & $p=0.08$ \\
\hline SVR. 3 & $1149.41 \pm 415.929^{* *}$ & $1453 \pm 445.448^{* * *}$ & $\mathrm{~F}=0.99$ & $p=0.32$ \\
\hline \multicolumn{5}{|l|}{$\left(\mathrm{ml} /\right.$ beat $\left./ \mathrm{m}^{2}\right)$} \\
\hline SVI. 1 & $27.333 \pm 6.624$ & $23.695 \pm 8.417$ & & \\
\hline SVI. 2 & $34.666 \pm 10.593^{*}$ & $32.260 \pm 9.497^{* * *}$ & $\mathrm{~F}=0.08$ & $p=0.77$ \\
\hline SVI. 3 & $34.333 \pm 11.446 \mathrm{nd}$ & $30.391 \pm 9.064^{* *}$ & $\mathrm{~F}=0.03$ & $p=0.86$ \\
\hline \multicolumn{5}{|l|}{$\left(\mathrm{gm} / \mathrm{m}^{2}\right)$} \\
\hline RVSWI. 1 & $9.925 \pm 6.326$ & $6.904 \pm 8.955$ & & \\
\hline RVSWI. 2 & $8 \pm 4.975 \mathrm{nd}$ & $6.2 \pm 5.434 \mathrm{nd}$ & $\mathrm{F}=1.46$ & $p=0.23$ \\
\hline RVSWI. 3 & $6.791 \pm 3.004^{*}$ & $6.108 \pm 5.149 \mathrm{nd}$ & $\mathrm{F}=2.48$ & $p=0.12$ \\
\hline \multicolumn{5}{|l|}{$\left(\mathrm{g} \cdot \mathrm{m} / \mathrm{m}^{2}\right)$} \\
\hline LVSWI. 1 & $24.35 \pm 9.286$ & $22.74 \pm 8.967$ & & \\
\hline LVSWI. 2 & $28 \pm 14.302 \mathrm{nd}$ & $29.53 \pm 9.477^{* *}$ & $\mathrm{~F}=1.86$ & $p=0.17$ \\
\hline LVSWI. 3 & $31.15 \pm 13.376 \mathrm{nd}$ & $30.79 \pm 12.041^{* *}$ & $\mathrm{~F}=0.04$ & $p=0.82$ \\
\hline
\end{tabular}

MAP: mean arterial pressure, CVP: central venous pressure, PA: pulmonary artery, Pcwp: pulmonary capillary wedge pressure, HR: heart rate, CO: cardiac output, CI: cardiac index, PVR: pulmonary vascular resistance, SVR: systemic vascular resistance, SVI: stroke volume index, RVSWI: right ventricular stroke work index, LWSWI: left ventricular stroke work index. 1: During anesthetic induction, 2: during weaning from cardiopulmonary bypass, $3:$ at $1 \mathrm{~h}$ in the postoperative period. ${ }^{*} p<0.05 ; * * p<0.01 ; * * * p<0.001 . \mathrm{n}=$ no difference (comparison between the value in each group and first value), \# Comparison between the values in the groups according to anesthesia induction. 
Table 4. Drugs Required in Weaning from Cardiopulmonary Bypass

\begin{tabular}{llcc}
\hline \hline No. of patients requiring & $\begin{array}{c}\text { Milrinone } \\
(n=24)\end{array}$ & $\begin{array}{c}\text { Control } \\
(n=23)\end{array}$ & $\begin{array}{c}p \\
\text { value }\end{array}$ \\
\hline $\begin{array}{l}\text { Vasodilator in wean- } \\
\text { ing from CPB }\end{array}$ & $4(16.6 \%)$ & $19(82.6 \%)$ & $0.001^{*}$ \\
\hline $\begin{array}{l}\text { Vasopressor in wean- } \\
\text { ing from CPB }\end{array}$ & $0(0 \%)$ & $5(21.7 \%)$ & $0.032^{*}$ \\
\hline $\begin{array}{l}\text { Inotropic agent in } \\
\text { weaning from CPB }\end{array}$ & $2(8 \%)$ & $11(47.8 \%)$ & $0.027^{*}$ \\
\hline $\begin{array}{l}\text { No. of arrhythmic at- } \\
\text { tack requiring antiar- } \\
\text { rhythmic drugs in }\end{array}$ & & & \\
weaning from CPB & & & \\
0 & 22 & 13 & $0.04^{*}$ \\
1 & 2 & 7 & \\
2 & 0 & 2 & \\
3 & 0 & 1 & \\
\hline
\end{tabular}

CPB: cardiopulmonary bypass, ${ }^{*} p<0.05$.

Table 5. Drugs Required in Postoperative Intensive Care Unit

\begin{tabular}{|c|c|c|c|}
\hline $\begin{array}{l}\text { No. of patients needing } \\
\text { nitroglycerine in ICU }\end{array}$ & $\begin{array}{l}\text { Milrinone } \\
(n=24)\end{array}$ & $\begin{array}{l}\text { Control } \\
(n=23)\end{array}$ & $\begin{array}{c}p \\
\text { value }\end{array}$ \\
\hline Day of surgery & $8(33.3 \%)$ & $17(73.9 \%)$ & $0.031^{*}$ \\
\hline Day 1 postoperatively & $6(26 \%)$ & $10(43 \%)$ & 0.463 \\
\hline \multirow{2}{*}{$\begin{array}{l}\text { No. of patients requir- } \\
\text { ing inotropic agents in } \\
\text { ICU }\end{array}$} & $n=24$ & $n=23$ & \\
\hline & Milrinone & Control & $\begin{array}{c}p \\
\text { value }\end{array}$ \\
\hline Day of surgery & $4(16.6 \%)$ & $6(26 \%)$ & 0.685 \\
\hline Day 1 postoperatively & $4(16.6 \%)$ & $6(26 \%)$ & 0.685 \\
\hline \multirow[t]{2}{*}{$\begin{array}{l}\text { No. of arrhythmic at- } \\
\text { tacks requiring antiar- } \\
\text { rhythmic drugs in } \\
\text { ICU }\end{array}$} & $n=24$ & $n=23$ & \\
\hline & $\begin{array}{l}\text { Milrinone } \\
(n)\end{array}$ & $\begin{array}{l}\text { Control } \\
(n)\end{array}$ & $\begin{array}{c}p \\
\text { value }\end{array}$ \\
\hline \multirow[t]{4}{*}{ Day of surgery } & 18 & 16 & \multirow{4}{*}{0.906} \\
\hline & 4 & 4 & \\
\hline & 2 & 2 & \\
\hline & 0 & 1 & \\
\hline
\end{tabular}

Day 1 postoperatively

$\begin{array}{rrrr}0 & 24 & 16 & \\ 1 & 0 & 3 & \\ 2 & 0 & 1 & 0.026^{*} \\ 3 & 0 & 2 & \\ 6 & 0 & 1 & \end{array}$

${ }^{*} p<0.05$. than in Grp II $($ Table 7$)(p<0.05)$.

\section{DISCUSSION}

Konstam and Cody ${ }^{22)}$ reported a 33\% increase in CI with milrinone $37.5 \mu \mathrm{g} / \mathrm{kg}$ loading and $0.375 \mu \mathrm{g} /$ $\mathrm{kg} / \mathrm{min}$ maintenance doses. They also found decreases in Pcwp and SVR by $24 \%$ and $15 \%$, respectively. We observed a 34\% increase in CI in Grp I and $37 \%$ in Grp II. On the other hand, SVR decreased by $36 \%$ and $39 \%$ in the two groups. In another study ${ }^{12}$ where $20 \mu \mathrm{g} / \mathrm{kg}$ and $40 \mu \mathrm{g} / \mathrm{kg}$ loading doses were compared during weaning from bypass, both groups showed similar CI values $\left(2.92 \mathrm{l} / \mathrm{min} / \mathrm{m}^{2}\right.$ vs. $2.91 \mathrm{l} /$ $\mathrm{min} / \mathrm{m}^{2}$ ) after bypass. However, the $20 \mu \mathrm{g} / \mathrm{kg}$ group showed a $30 \%$ rate of hypotensive episodes requiring vasopressor use in comparison to $90 \%$ in the other group. ${ }^{12)}$ We also noted mild decreases in MAP in Grp I at $1 \mathrm{~h}$ postoperatively, but inotropic and vasopressor drugs were not used significantly more than in Grp II.

It is noteworthy that PAP, Pcwp, and CVP decreased more in Grp I than in Grp II during weaning from CPB in our study with a $25 \mu \mathrm{g} / \mathrm{kg}$ loading dose of milrinone given over $20 \mathrm{~min}$, followed by a $0.25 \mu \mathrm{g} / \mathrm{kg} / \mathrm{min}$ maintenance dose in Grp I $(p<$ $0.05)$.

CI increased in a similar manner in both groups; however, nitroglycerine and vasopressor use as well as inotropes and antiarrhythmic agent use were more common in Grp II. It is generally accepted that a better performance during weaning from CPB with milrinone results in a more favorable long-term outcome. Milrinone is most beneficial in acute excerbations of CHF. 4,6,23).

Boomers et al. ${ }^{16)}$ compared the effects of intravenous nitroglycerine $(2 \mu \mathrm{g} / \mathrm{kg} / \mathrm{min})$ and milrinone $(50 \mu \mathrm{g} / \mathrm{kg}$ loading and $0.5 \mu \mathrm{g} / \mathrm{kg} / \mathrm{min}$ maintenance dose) in patients with pulmonary hypertension $(>25 \mathrm{mmHg})$ after mitral valve surgery and reported a more significant increase in $\mathrm{CO}$ in the milrinone group, whereas changes in PVR and MPAP were similar in both groups. In our study, Grp I demonstrated a more prominent decrease in PVR clinically in spite of the fact that we used lower doses of milrinone than Boomers et al. ${ }^{16)}$ and that Grp II had higher rate of nitroglycerine use than Grp I.

As noted before, the postoperative period was less eventful in Grp I although milrinone was not given in this period. This was confirmed by the observation 
Table 6. Hematologic Profiles

\begin{tabular}{|c|c|c|c|c|}
\hline & $\begin{array}{c}\text { Milrinone } \\
n=24\end{array}$ & $\begin{array}{c}\text { Control } \\
n=23\end{array}$ & \multicolumn{2}{|c|}{$\begin{array}{l}\text { Two tailed } \\
\text { significance }\end{array}$} \\
\hline & & & & \\
\hline RBC. 2 & $3.02 \pm 0.511^{* * *}$ & $3.04 \pm 0.397^{* * *}$ & $\mathrm{~F}=0.03$ & $p=0.85$ \\
\hline RBC. 3 & $2.92 \pm 0.461^{* * *}$ & $2.88 \pm 0.321^{* * *}$ & $\mathrm{~F}=0.002$ & $p=0.96$ \\
\hline RBC. 4 & $3.49 \pm 0.452^{* * *}$ & $3.34 \pm 0.46^{* * *}$ & $\mathrm{~F}=0.60$ & $p=0.30$ \\
\hline Hb. 1 & $11.81 \pm 1.49$ & $13.6 \pm 1.5$ & & \\
\hline Hb. 2 & $8.06 \pm 1.162^{* * *}$ & $8.9 \pm 1.134^{* * *}$ & $\mathrm{~F}=2.92$ & $p=0.09$ \\
\hline Hb. 3 & $8.06 \pm 0.647^{* * *}$ & $8.41 \pm 0.995^{* * *}$ & $\mathrm{~F}=8.70$ & $p=0.0050$ \\
\hline Hb. 4 & $9.76 \pm 1.256^{* * *}$ & $9.74 \pm 1.351^{* * *}$ & $\mathrm{~F}=8.390$ & $p=0.0058$ \\
\hline Hct. 1 & $36.4 \pm 4.521$ & $34.54 \pm 4.445$ & & \\
\hline Hct. 2 & $24.69 \pm 3.769^{* * *}$ & $26.6 \pm 3.506^{* * *}$ & $F=1.68$ & $p=0.20$ \\
\hline Hct. 3 & $24.29 \pm 2.485^{* * *}$ & $25.17 \pm 2.904^{* * *}$ & $\mathrm{~F}=3.48$ & $p=0.06$ \\
\hline Hct. 4 & $29.14 \pm 3.801^{* * *}$ & $28.08 \pm 6.679^{* * *}$ & $\mathrm{~F}=2.05$ & $p=0.15$ \\
\hline Plat. 1 & $257.333 \pm 44.429$ & $218.086 \pm 38.004$ & & \\
\hline Plat. 2 & $160.916 \pm 49.144^{* * *}$ & $125.130 \pm 32.949$ & $\mathrm{~F}=0.07$ & $p=0.79$ \\
\hline Plat. 3 & $136.666 \pm 50.603^{* * *}$ & $108.478 \pm 25.373$ & $\mathrm{~F}=0.22$ & $p=0.64$ \\
\hline Plat. 4 & $313.916 \pm 94.781^{*}$ & $292.652 \pm 112.197$ & $\mathrm{~F}=0.95$ & $p=0.33$ \\
\hline WBC. 1 & $7.733 \pm 2.539$ & $8.047 \pm 4.193$ & & \\
\hline WBC. 2 & $14.308 \pm 5.006^{* * *}$ & $12.952 \pm 3.859^{* * *}$ & $\mathrm{~F}=1.19$ & $p=0.28$ \\
\hline WBC. 3 & $12.683 \pm 2.961^{* *}$ & $13.921 \pm 4.685^{* * *}$ & $\mathrm{~F}=1.40$ & $p=0.24$ \\
\hline WBC. 4 & $11.65 \pm 3.440^{*}$ & $10.008 \pm 3.434 \mathrm{nd}$ & $\mathrm{F}=1.08$ & $p=0.30$ \\
\hline
\end{tabular}

RBC: red blood cell $\left(\times 10^{3} / \mathrm{mm}^{3}\right), \mathrm{Hb}$ : hemoglobin $(\mathrm{mg} / \mathrm{dl}), \mathrm{Hct}$ : hematocrit (\%), Plat: platelet (platelets/ microlitre, WBC: white blood cell $\left(\times 10^{9} / 1\right), 1$ : preoperative, 2: postoperative minute 30, 3: postoperative day 1, 4: postoperative day 7. ${ }^{*} p<0.05 ; * * p<0.01 ; * * * p<0.001$. nd $=$ no difference (comparison between the value in each group and first value). ${ }^{*}$ Comparison between the value in the groups accordimg to preop.

Table 7. Fluid Balances (ml)

\begin{tabular}{cccccc}
\hline \hline Group & Level & \multicolumn{1}{c}{ Mean } & \multicolumn{1}{c}{ S. D. } & \multicolumn{1}{c}{ Median } & Significance* $^{*}$ \\
\hline Milrinone & 1 & 1.458 .333 & 1.136 .706 & 1.450 .000 & $\chi^{2}=46.083$ \\
\hline & 2 & 733.333 & 1.227 .215 & 675.000 & $p<0.001$ \\
\hline Control & 1 & -56.666 & 622.873 & -52.000 & \\
\hline & 2 & -156.956 & 837.677 & -160.000 & $p<0.001$ \\
\hline & 3 & -738.695 & 738.695 & -880.000 & \\
\hline
\end{tabular}

1: during surgery, 2: day of surgery in ICU, 3: day 1 postoperatively in ICU. ${ }^{*}$ Friedman test.

that Grp I used less nitroglycerine and antiarrhythmic $(p<0.05)$. The half-life of milrinone varies between $50 \mathrm{~min}$ and $7 \mathrm{~h}$, which may explain for the favorable outcome in the immediate postoperative period; com- parable benefits of the drug in later periods could be due to better performance during weaning from extracorporeal circulation and its effects in the long term. 
Our hematologic findings are comparable to the study by Kikura et al. ${ }^{15)}$ who reported that no significant hematologic change occurred when patients were given milrinone after CPB. They observed no case of surgical hemorrhage necessitating transfusion or reoperation. A $2 \%$ incidence of thrombocytopenia in the study by Konstam et al. ${ }^{22)}$ is comparable to our results of similar hematologic profiles in the two groups. In addition, we observed an insignificant increase in hemorrhage from chest tubes in Grp I. However, the statistically significant difference between the two groups for $\mathrm{Hb}$ levels was not significant clinically.

In our analysis, we observed a significant trend toward a positive intraoperative fluid balance in Grp I; this difference was more obvious in the ICU management necessitating more diuretics and management for a negative balance in Grp II to maintain stable cardiac performance. Cody ${ }^{24)}$ noted that milrinone increases total blood volume by vasodilation. Our findings are not considered to be attributable the vasodilatory effects of the drug but rather due to favorable effects on intrinsic myocardial performance since the drug was not given in the ICU.

Feneck et al. ${ }^{18)}$ compared dobutamine and milrinone in open heart surgery patients with pulmonary hypertension and found a similar increase in $\mathrm{CI}$ in both groups; nevertheless, Pcwp and PAP were reduced significantly in the milrinone group. They used higher doses of milrinone in that study. Dobutamine as well as other inotropes such as dopamine and adrenaline increase myocardial oxygen consumption along with an increase in myocardial performance. ${ }^{2,25,26)}$ Early weaning from CPB with dopamine infusion was compared to weaning $30 \mathrm{~min}$ later without dopamine and more cardiac edema and a reduction in contractility and compliance was seen with dopamine. ${ }^{26)}$ Milrinone, however, is assumed to increase myocardial contractility without an increase in myocardial oxygen consumption. ${ }^{5,22,26)}$ Such a depletion in aerobic pathways, especially in patients with heart failure, may cause devastating clinical decompensation with further deterioration of intrinsic myocardial function. ${ }^{26)}$ Milrinone may be preferable in these situations.

Lower doses of milrinone provide a vasodilatory response; the inotropic response follows a dosedependent pattern. The relatively longer half-life of this drug is advantageous over other inotropic, vasopressors, and vasodilator medications commonly used in cardiac surgery. ${ }^{25)}$

\section{CONCLUSIONS}

We conclude that milrinone has favorable effects in patients with heart failure and during weaning from CPB in high-risk patients due to its aforementioned benefits. The use of a single drug with dose-dependent effects is also advantageous from the clinical point of view. The $25 \mu \mathrm{g} / \mathrm{kg}$ loading and $0.25 \mu \mathrm{g} / \mathrm{kg} / \mathrm{min}$ maintenance dose provided adequate cardiac performance causing a greater reduction in PAP and Pcwp, with CVP and MAP in the normal range, than previously appreciated.

Less need for additional medication, low rate of side effects, and highly skilled for nursing care make low-dose milrinone suitable for routine use during weaning from CPB in patients with mitral stenosis and pulmonary hypertension.

\section{REFERENCES}

1) Doolan L. A., Jones E. F., Kalman J., J. Cardiothorac. Vasc. Anesth., 1, 37-41 (1997).

2) Monrad E. S., Baim D. S., Smith H. S., Circulation 3 Pt 2, III168-74 (1986).

3) Honerjager P., Am. Heart J. 6 Pt 2, 19391944 (1991).

4) Boger J. E., DeLuca S. L., Watkins D. F., Vershave K. K., Thomley A. M., J. Intraven. Nurs., 3, 148-154 (1997).

5) Baim D. S., Am. J. Cardiol., 12, 23A-26A (1989).

6) Levy J. H, Bailey J. M, Deeb G. M., Ann. Thorac. Surg., 1, 325-330 (2002).

7) Sun M., Dawood F., Wen W. H., Chen M., Dixon I., Kirshenbaum L. A., Liu P. P., Circulation, 20, 3221-3228 (2004) Epub 2004, Nov 8.

8) Rakhit R. D., Seiler C., Wustmann K., Zbinden S., Windecker S., Meier B., Eberli F. R., Coron. Artery Dis., 3, 147-152 (2005).

9) Shai J., Schulze M. B., Manson J. E., Rexrode K. M., Stampfer M. J., Mantzoros C., Hu F. B., Diabetes Care, 6, 1376-1382 (2005) .

10) Kosmala W., Przewlocka-Kosmala M., Mazurek W., Int. J. Cardiol., 3, 449-456 (2005) .

11) Berry M. F., Woo Y. J., Pirolli T. J., Bish L. T., Moise M. A., Burdick J. W., Morine K. J., 
Jayasankar V., Gardner T. J., Sweeney H. L., J. Heart Lung Transplant., 9, 1061-1068 (2004).

12) DeHert S. G., Moens M. M, Jorens P. G., J. Cardiothorac. Vasc. Anesth., 3, 264-271 (1995).

13) Das P. A., Skoyles J. R., Sherry K. M., Peacock J. E., Fox P. A., Woolfrey S. G., Br. $J$. Anesth., 4, 426-429 (1994).

14) Bailey J. M., Levy J. H., Kikura, M., Szlam F., Hugg Jr. C. C., Anesthesiology, 3, 616622 (1994).

15) Kikura M., Lee M. K., Safon R. A., Bailey J. M., Levy J. H., Anesth. Analg., 1, 44-48 (1995) .

16) Boomers O. W., Duncan F., Feneck R. O., Oral Session, European Association of Cardiothoracic Anesthesiologists-1995 (EACTA 95) Madrid Spain.

17) De Hert S. G., Vermeyen K. M., Anesth. Analg., 5, 1110-1 (1996).

18） Feneck R. O., Sherry K. M., Withington P. S., Oduro-Dominah A., European Milrinone Multicenter Trial Group, J. Cardiothorac.
Vasc. Anesth., 3, 306-315 (2001).

19) Janelle G. M., Urdaneta F., Blas M. L., Shryock J., Tang Y. S., Martin T. D., Lobato E. B., Anesth. Analg., 6, 1377-1383 (2001).

20) Hoffman T. M., Wernovsky G., Atz A. M., Kulik T. J., Nelson D. P., Chang A. C., Bailey J. M., Akbary A., Kocsis J. F., Kaczmarek R., Spray T. L., Wessel D. L., Circulation, 7, 996-1002 (2003).

21) Baltimore J. J., J. Perianesth. Nurs., 4, 246254 (2001).

22) Konstam M. A., Cody R. J., Am. J. Cardiol., 12, 822-826 (1995).

23) Yamada T., Takeda J., Katori N., Tsuzaki K., Ochiai R., J. Cardiothorac. Vasc. Anesth., 4, 367-373 (2000).

24) Cody R. J., Am. J. Cardiol., 2, 31A-34A (1989).

25) Seino Y., Momomura S. I., Takano T., Hayakawa H., Katoh K., Crit. Care Med., 9, 1490-1497 (1996).

26) Ramsay J. G., Abstract Lectures, European Association of Cardiothoracic Anesthesiologists-1995 (EACTA 95) Madrid Spain. 